\title{
Ion transport for enthusiasts
}

\section{N. Michael Green}

The Sarcoplasmic Reticulum: Transport and Energy Transduction. By Leopoldo de Meis. Pp.163. ISBN 0-471-05025-3. (Wiley:1981.) £29.25, \$52.50.

OVER the past 12 years the sarcoplasmic reticulum has become increasingly popular as a model system for the study of transport of ions across membranes. Physiology, electron microscopy, techniques of membrane reconstitution, lipid chemistry, protein chemistry and enzyme kinetics have all contributed to make this one of the best known of subcellular organelles.

This short monograph is concerned with the author's own field of kinetic studies on isolated vesicles of sarcoplasmic reticulum, to which he has made significant contributions. After two concise and informative introductory chapters, Dr de Meis restricts himself to this area. By concentrating his attention in this way he is able to present a variety of steady state and transient state kinetic experiments which have led to the generally accepted minimal cycle of at least eight reversible reactions that are responsible for $\mathrm{Ca}^{+}+$translocation. Since $\mathrm{Ca}^{++}, \mathrm{Mg}^{++}$and ATP each enter the cycle more than once, it has required considerable experimental ingenuity to provide even a qualitative description of the reaction sequence. The chief merit of the book is that it presents crucial experiments from many laboratories in well-illustrated detail, providing a valuable perspective for anyone trying to find his way through the 300 or more papers quoted. Mastery of the evidence presented will bring the reader to the end of 1980 and to a good position from which to cope with the arguments of 1981 and beyond, for the story is by no means over.

The author says very little on several important questions on which the evidence is conflicting and it would have been helpful to have had these problems more clearly delineated. They include the related questions of a monomeric versus a dimeric functional unit and of the number of $\mathrm{Ca}^{++}$ and ATP binding sites per peptide chain. The questions of co-transport or countertransport of other ions and of the possible electrogenic nature of the pump are barely considered, while excitation-contraction coupling and $\mathrm{Ca}^{++}$release mechanisms are explicitly excluded.

The final chapter on the role of water in the active site of the ATPase is rather speculative, being based in part on the effects on the stability of the acyl phosphate of dimethylsulphoxide, which is assumed to be a hydrophobic solvent; this assumption is hardly warranted by its very high dielectric constant. The remarkable changes in reactivity undergone by the acyl phosphate intermediate during the catalytic cycle are more likely to be a consequence of local electronic influences than of a general change in accessibility of the catalytic site to water.

These are minor reservations, however, and do not seriously detract from the value of this book to all those interested in an analytical approach to ion transport.

N. Michael Green is in the Division of Biochemistry, National Institute for Medical Resegrch, Mill Hill, London.

\section{Intention in mind}

\section{Richard Gregory}

Mind Design: Philosophy, Psychology, Artificial Intelligence. Edited by John Haugeland. Pp.368. Hbk ISBN 0-22608110-5; pbk ISBN 0-226-58052-1. (MIT Press: 1981.) Hbk $\$ 21.50, £ 13.50$; pbk $\$ 10$, £6.20. Minds and Mechanisms: Philosophical Psychology and Computational Models. By Margaret A. Boden. Pp.311. ISBN 0-855-27064-0. (Harvester/Cornell University Press: 1981.) $£ 20, \$ 29.50$.

Mind Design, a collection of 12 papers by computer scientists and philosophers of AI, was conceived by its editor, John Haugeland, as a sequel to A.R. Anderson's Minds and Machines which was published by Prentice-Hall in 1964. This new collection offers essays by Allen Newell and Herbert Simon; Zenon Pylyshyn; Marvin Minsky; Drew McDermott; Hubert Dreyfus; Hilary Putnam; Daniel Dennett; John Searle; Jerry Fodor; and Donald Davidson. There is also the particularly welcome essay, "Artificial Intelligence - A Personal View”, by David Marr, whose recent death while at the height of his genius was a tragic blow for computer vision as well as for his many friends. The editor himself contributes an insightful Introduction, "Semantic Engines", and a rather less interesting essay on cognitivism.

In his Introduction, Haugeland asks how the psychology of thought can be properly scientific when thoughts cannot be observed; though the problem is not like that of galaxies or electrons, that they are too far away or too small. Referring to the "marvellously rich analogy with computers", and especially to a chessplaying machine, which "would be awkward to describe [in] its functioning by assigning geometrical shapes and locations to the internal program routines, yet has no immaterial soul" the crucial question is raised: how far is the human chess player like the machine that may beat him in intellectual combat?

A central issue throughout the book is

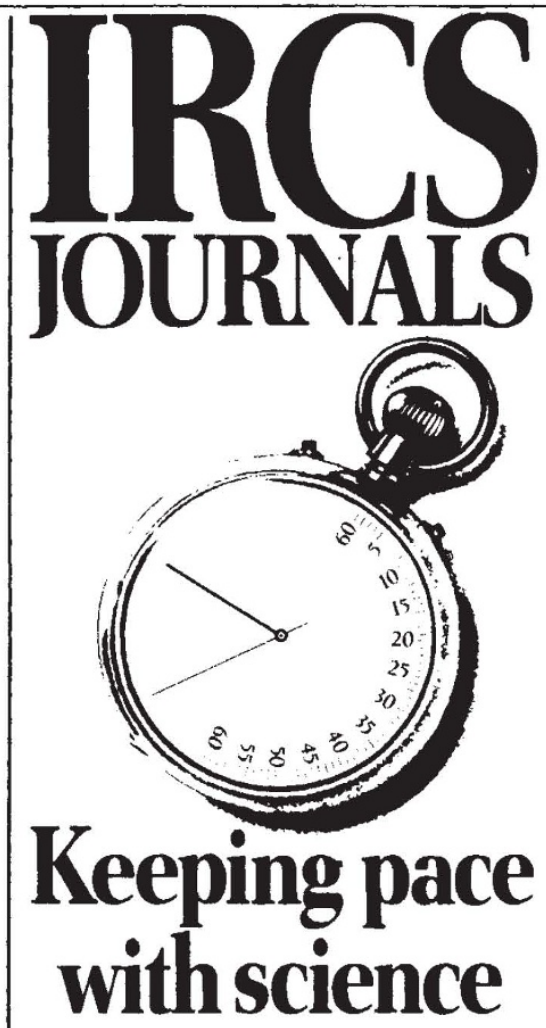

IRCS Medical Science St. Leonard's House St. Leonardgate, Lancaster, U.K.

A member of Elsevier Science Puhlishers Circle No.03 on Reader Enquiry Card.

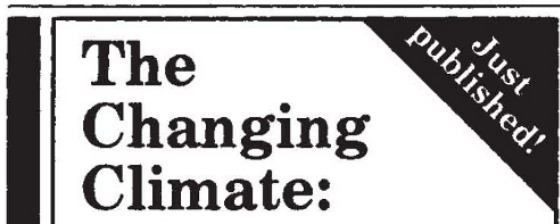

Responses of the Natural Flora and Fauna

Michael J. Ford,

Nature Conservancy Council

Choosing a wide range of natural examples, Dr Ford considers the different levels at which climatic effects operate on individual species and communities. Although the magnitude of climatic change this century is quite small, the author argues that its effect on natural flora and fauna may be disproportionate. Man's destruction of natural habitats includes climatically favourable areas providing refuge in times of climatic stress. If these disappear, certain species may be endangered.

April $1982 \quad 190 \mathrm{pp}$

0045740178 Hardback $£ 13.95 / \$ 27.50$

George Allen \& Unwin (Publishers) Ltd, PO Box 18, Park Lane.

Hemel Hempstead. Herts HP2 4TE, England. Allen \& Unwin Inc

9 Winchester Terrace.

Winchester, MA 01890, USA 